\title{
DIGITAL EARTH AS NEXT STEP IN CARTOGRAPHY
}

DOI: http://dx.doi.org/10.18509/GBP.2017.17

UDC: 528.9:[004:523.31

\author{
Eugene Eremchenko ${ }^{1}$ \\ Svemir Gorin ${ }^{2}$ \\ Vladimir Tikunov ${ }^{1}$ \\ Ivan Radevski \\ ${ }^{1}$ Lomonosov Moscow State University, Russia \\ ${ }^{2}$ Ss. Cyril and Methodius University, Faculty for Natural Sciences and Mathematics, Institute for \\ Geography, Macedonia
}

\begin{abstract}
Emerging of Google Earth in 2005 was perceived as significant achievements in geospatial sciences and bring into focus of mass attention the concept of Digital Earth, manifested seven years before by ex-vice-president of USA Al Gore. Nevertheless, scientific origins of Digital Earth and its relations with cartography still unclear. We investigate both problems and propose the vison of Digital Earth as a quantum leap in cartography method, or scientific revolution in the terms of Thomas Kuhn. Proposed vision of Digital Earth and extended classification of cartography methods, as well as its interdisciplinary impact, are explained and discussed.
\end{abstract}

Keywords: Digital Earth, Google Earth, Google Maps, cartography, decision making, situation awareness, sustainable development, neogeography, virtual geographic environments, holography.

\section{INTRODUCTION}

In the beginning of XXI century new generation of geospatial services was emerged. Most remarkable milestone was the almost simultaneous start of new geoservices Google Maps and Google Earth (both started in 2005 and envisioned by Al Gore [1]). Google Maps became first so-called 'geoportals' - online cartographic services with rich representation of context by the means of satellite images instead of maps. On the contrary, Google Earth incorporates totally new approach. Google Earth is a virtual Earth represented by the remote sensing data in same manner as Google Maps, but without cartographic projection to the screen. Instead, virtual Earth hovered behind the screen, and user could interactively and seamlessly manipulate both scale and direction of sight. Google Earth allows generate even impossible, from cartographic point of view, directions of sight for example, direction 'down up'. Google Earth seems very like ordinary Globe, but it is not a Globe as a cartographic (i.e., scale-dependent) model of surface of Earth. Instead, it is a geocentric environment, that include surface of Earth, but goes far beyond and includes as well as geotagged images, panoramas, 3D-models of different objects and processes within geocentric environment regardless of scale, location and type of projection. These 3D-models are significant or even essential part of the Google Earth (Figure 1); the model of Earth itself is framework for aggregation of different user datasets (so-called mashups). 


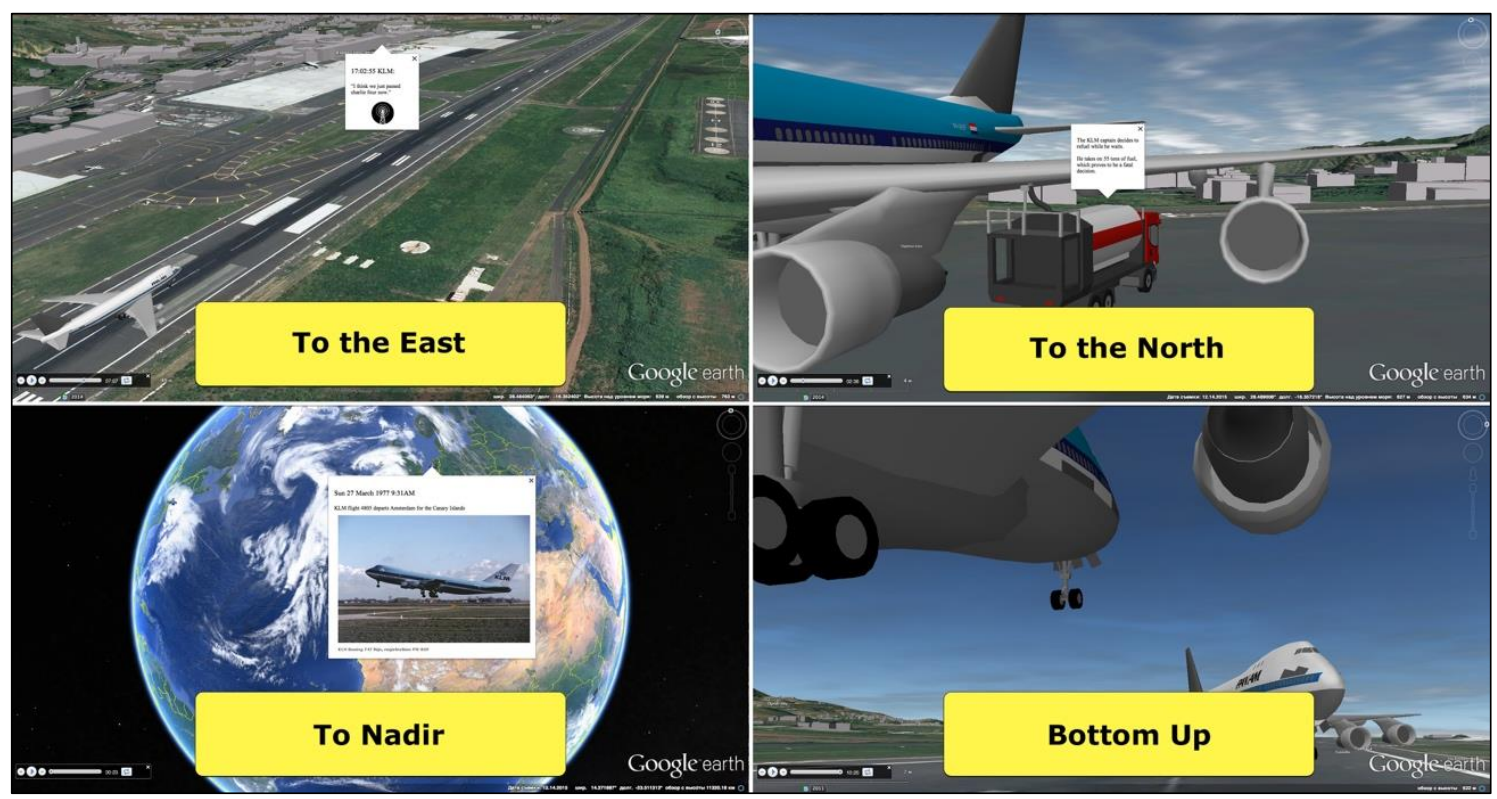

Figure 1. Dynamic spatial-temporal model of aviation catastrophe within Google Earth framework.

Digital Earth makes possible scale-independent and projection-independent visualization even with impossible for classic cartography direction of sight, for example from nadir to zenith. Model: PMOlsen, 2010. From: Eremchenko, Tikunov, 2016 [5].

Google Earth has three significant features.

First of all, Google Earth is a scale-independent and projection-independent model of Earth.

Secondly, it is true geocentric environment for aggregating a 3D-models of objects without its projection to surface as cartography does. Unlike Globe, Google Earth includes model of Earth surface as single universal, scale-independent framework for integrating 3D-models of user data. This surface model composed from satellite images; however, it could include map data as option too.

Thirdly, due to use of satellite images Google Earth allows asynchronous updating of information. Therefore, it opens breathtaking possibilities for creating true and rich 4Dmodels of different scales and accumulate them within same universal scale-independent framework.

Above mentioned properties show Google Earth as 'impossible object' from the point of view of classic cartography. For example, classic cartography divide all maps onto two different classes - geographical and topographical maps, and directly forbids creating of global and detailed, topographical map - as Google Earth and Google Maps do. Therefore, the new products at least greatly expand the possibilities of classic cartography. The reasons for such expansion should be investigated.

\section{DISCUSSION}

Solving of this problem requires clear understanding of nature of through a comparative analysis of the different approaches, the creation of their classification and typology. These problems are still being discussed.

In the first analysis of Google Earth and Google Maps Andrew Turner defines Neogeography in 2006 as a new class, or realm, of geospatial products, completely separated from the realm of ordinary maps and GIS. Therefore, from this point of view geospatial domain should be divided into two big realms of products - maps and GIS, 
from one side, and 'neogeography', from opposite side. Also, he made first attempt to define neogeography [2]:

Neogeography means "new geography" and consists of a set of techniques and tools that fall outside the realm of traditional GIS, Geographic Information Systems. Where historically a professional cartographer might use ArcGIS, talk of Mercator versus Mollweide projections, and resolve land area disputes, a neogeographer uses a mapping API like Google Maps, talks about GPX versus KML, and geotags his photos to make a map of his summer vacation. Essentially, Neogeography is about people using and creating their own maps, on their own terms and by combining elements of an existing toolset. Neogeography is about sharing location information with friends and visitors, helping shape context, and conveying understanding through knowledge of place.

Lastly, neogeography is fun.

Unfortunately, this mind-provoking definition is extensional instead of intensional and could not be used to refer the product to a particular realm.

First intensional definition of new products was proposed in 2008 [3]:

Neogeography is a new generation of geospatial products which differs from the previous one (maps and GIS) by three features:

- geocentric coordinates, not mapping projections;

- using raster, not vector for representation of geospatial context;

- using hypermedia as transport for semantics.

Obviously, this definition identifies neogeography and Digital Earth, therefore services like Google Maps should be considered as third distinct group of geospatial products. This definition shed light on the evolution of geospatial products, i.e. provide typology of the geospatial approaches [4]. There are two fundamental factors of limitations of visual perception and errors in decision making for any kind of visualization: 1) scale dependency, or lack of ability to interactive and seamless changing of scale by user, and 2) projection dependency, or lack of ability to interactive and seamless changing of direction of sight by user. In other words, there is strong demand for the providing of scale-independent and projection-independent approaches for the visualization and, in particular, for the geospatial visualization. Projection-independent visualization wellknown as 'holography'.

Classical geospatial products like maps and GIS are scale-dependent and projectiondependent due to three fundamental limitations of the cartographic method: 1) generalization, 2) projection, and 3) object layered representation. On the opposite side, Digital Earth (or neogeography) is scale-independent and projection-independent approach. Third type of geospatial products like Google Maps (well-known as 'geoportals') provides limited interactive scalability, but does not provides projectionindependency. Therefore, this class is intermediate, palliative approach. Another palliative is ordinary globes that provide projection-independent, but scale-dependent visualization (Figure 2). 


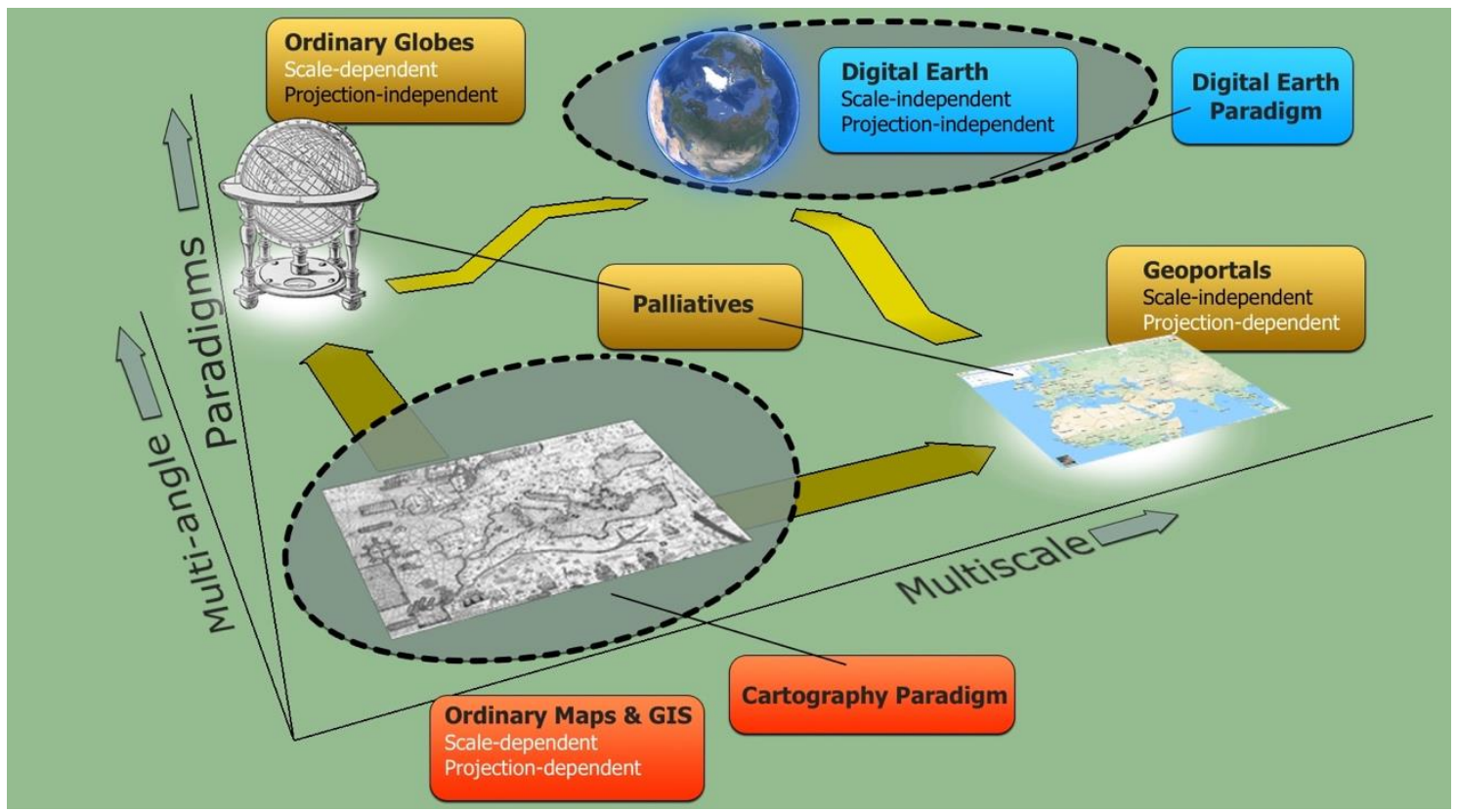

Figure 2. Visual representation of evolution of cartography from classic paradigm to Digital Earth paradigm through palliatives.

From the scope of proposed scheme Digital Earth is ultimate geospatial visualization that combines simultaneously holographic and scale-independency options for the user. Therefore, it is possible to consider it as 'superholography', or best possible approach for the visualization [5].

Significant differences between three types of geospatial approaches based on different ways of processing raw data. Maps and GIS are inevitably and intensionally reduced by the cartographer due to layering, projection and generalization. Instead, Digital Earth based on accessibility to unreduced (i.e., unprojected and ungeneralized data); user can process these raw data interactively and select the desired scale and direction of view [6]. Fundamental differences between the three approaches are collected in Table 1.

Table 1. Differences between classic cartography paradigm and Digital Earth paradigm.

\begin{tabular}{l|r|r}
\multicolumn{1}{c|}{ Property } & Classic Cartography Paradigm & Digital Earth Paradigm \\
\hline Mathematics & Projection & Similarity \\
\hline Datasets & Reduced & Unreduced \\
\hline Dimensions & 2D & 3D \\
\hline Measurability & Limited & Unlimited \\
\hline Situational Awareness & Limited & Full \\
& \multicolumn{2}{|c}{ Source: Eremchenko, Tikunov et al, 2015 }
\end{tabular}

Significant differences between two opposite types of approaches - maps and GIS, from one side, and Digital Earth, from another side, allow to consider Digital Earth as a new paradigm, or scientific revolution in terms of Thomas Kuhn [7]. Google Earth and other geospatial services based on Digital Earth paradigm became a result of an interruption of 'normal science' in cartography, which lasted several millennia, through adopting of new geospatial paradigm in the beginning of XXI century. 


\section{INTERDISCIPLINARY IMPACTS}

As any scientific revolution, Digital Earth impacts different fields of knowledge, social and technological practices. Let's take a closer look at impacts on semiotics and sustainable development.

Scientific essence of classic cartography is representation of Earth by means of signs. In process of historical development of a cartography cartographic signs were becoming more and more elaborated; 50 years ago, in 1967, the comprehend theory of visual signs was proposed by Jacques Bertin [8]. Instead, Digital Earth and geoportals both based on images instead of cartographic signs, clearly retreat to basics. Images could be considered as very simple signs, so-called 'iconic images'. Classic sample of iconic image is picture created by person. Nevertheless, modern remote sensing data like satellite images, spherical panoramas, etc., have minimum subjectivity and are much close to immediate perception than to perception mediated by signs. It is reasonable to consider photographic images, in particular, remote sensing data as a 'signless' media, or specific 'zero-signs', or direct analogue of zero in mathematics [9]. Therefore, zero-sign could be defined as media for meaning that is not a sign. Zero-sign concept should be fruitful, for example, for the understanding of nature of very effective decision-making in wild life.

New paradigm impacts on sustainable development too. United Nations defines sustainable development as [10]:

development that promotes prosperity and economic opportunity, greater social wellbeing, and protection of the environment - offers the best path forward for improving the lives of people everywhere,

and explains its goal:

achieve international co-operation in solving international problems of an economic, social, cultural, or humanitarian character and in promoting and encouraging respect for human rights and for fundamental freedoms for all without distinction as to race, sex, language, or religion.

Therefore, sustainable development addressed directly to harmonization of decisionmaking processes throughout the World and throughout different hierarchical levels (personal, local, regional, global) [11]. Concept of effective decision-making support is situation awareness [12]. Harmonization of decision-making demands single, universal scale-dependent geospatial framework for different scales and different, interactively selected projections. Nevertheless, existing of single universal global-wide framework is directly prohibited by fundamental principles of classic cartography. Therefore, scaleindependent and projection-independent Digital Earth makes single universal worldwide framework possible. From this point of view, Digital Earth is ultimate environment for the situation awareness that provides way for the better decision-making and better quality of life.

\section{CONCLUSIONS}

Digital Earth is a new scientific paradigm within cartography domain, that provides true scale-independency and projection-independency. This new paradigm impacts different fields of knowledge, especially semiotics and sustainable development. Interdisciplinary approach for studying Digital Earth should be recommended.

\section{ACKNOWLEDGEMENTS}

The study was supported by grant of the Russian Science Foundation (project \#15-1730009). 


\section{REFERENCES}

[1] Gore, Al. The Digital Earth: Understanding our planet in the 21st Century, Al Gore speech at California Science Center, Los Angeles, California, on January 31, 1998. http://www.isde5.org/al_gore_speech.htm. Accessed 20 Feb 2017.

[2] Turner, A., 2006. Introduction to neogeography. Sebastopol, CA: O’Reilly. P. 54.

[3] Eremchenko, E. N. Neogeografiya: osobennosti i vozmozhnosti (Russian). Materialyi konferentsii "Vyisokie tehnologii XXI veka" IX Mezhdu-narodnogo foruma "Vyisokie tehnologii XXI veka, pp. 170-170. Moskva, 2008.

[4] Eremchenko, E., Tikunov, V., Ivanov, R., Massel, L., Strobl, J. Digital Earth and Evolution of Cartography. Procedia computer science. 2015. Vol. 66, no. C. pp. 235-238.

[5] Eremchenko, E., Tikunov, V. Golograficheskie vozmozhnosti vizualizatsii v geografii (Russian). Vestnik Moskovskogo universiteta. Seriya 5: Geografiya. 2016. No. 2 pp. 22-29.

[6] Tikunov V.S., Eremchenko E. N. Digital Earth and Cartography. Geodesy and Cartography (Russian). 2015, 905(11), pp. 6-15. DOI: 10.22389/0016-7126-2015-905-11-6-15

[7] Kuhn, T. The Structure of Scientific Revolutions. The University of Chicago, Chicago, 1970 (2nd edition, enlarged), $210 \mathrm{p}$.

[8] Bertin J. The semiology of graphics. English Edition. Madison: University of Wisconsin Press, 1983.

[9] Eremchenko, E. N. Kontseptsiya znaka v kontekste neogeografii (Russian). Informatsionnyie i matematicheskie tehnologii v nauke i upravlenii. Nauchnyiy zhurnal, 27, 1 (2016), pp. 49-54.

[10] UN official site. What we do. http://www.un.org/en/sections/what-we-do/ Accessed 08 March 2017.

[11] Pyankov, S. V., Tikunov, V. S. Geographic information for sustainability. ICA News, 2011, no. 57 , pp. $14-15$.

[12] Endsley, M.R. Design and evaluation for Situation Awareness enhancement. Proceedings of the Human Factors Society 32nd Annual Meeting (Volume 1, pp. 97 - 101). Santa Monica, CA: Human Factors Society. 